\title{
LIFE HISTORY OF ANTAEOTRICHA SP. (LEPIDOPTERA: OECOPHORIDAE: STENOMATINAE) IN PANAMA*
}

\author{
By Annette Aiello \\ Smithsonian Tropical Research Institute \\ P. O. Box 2072, Balboa, Panama
}

The subfamily Stenomatinae (Oecophoridae) is a New World microlepidopteran group of approximately 35 genera and more than 1200 species. Its range is from the United States through Argentina; South America is especially rich in species. Little is known of the biology of these moths, but those that have been studied include leaf miners, stem borers, and seed eaters. The genus Antaeotricha Zeller, of similar range, comprises more than 400 species, many of which are leaf tiers.

Three individuals of Antaeotricha sp. near fractilinea (Walsingham) (Figure 1) were reared from larvae collected 29 March through 4 April 1980 on Barro Colorado Island (BCI), Panama. Two additional individuals were preserved, one in its final instar, the other as a pupa.

The larvae had constructed tubes (Figure 2) of silk, frass, and cast head capsules, on the undersides of the leaves of Mascagnia nervosa (Malpighiaceae).

At the time of collection two of the three larvae were in their final instar and these pupated five days later. The third individual, probably a first instar judging from its small size and tiny tube, molted the day after collection. Due to the uncertainty regarding instar number, letters instead of numbers are used to refer to instars.

Mascagnia nervosa is a liana which grows into the canopy of the BCI forest. Seedlings are found frequently around the edges of clearings and in tree falls. Antaeotricha larvae were common on the older leaves of plants $10-30 \mathrm{~cm}$ tall and bearing three to eight leaves each; some leaves supported as many as four larval tubes, although one or two were most common. Possibly Antaeotricha attacks leaves of this plant in the forest canopy as well.

Head capsule widths (Table 1) ranged from $0.18 \mathrm{~mm}$ (instar A) to $1.38 \mathrm{~mm}$ (final instar). Instar durations for the larva collected as instar A were: 5(B), 4(C), 4(D), 3(E), 5(F), and 8(G) days.

*Manuscript received by the editor September 14, 1981. 


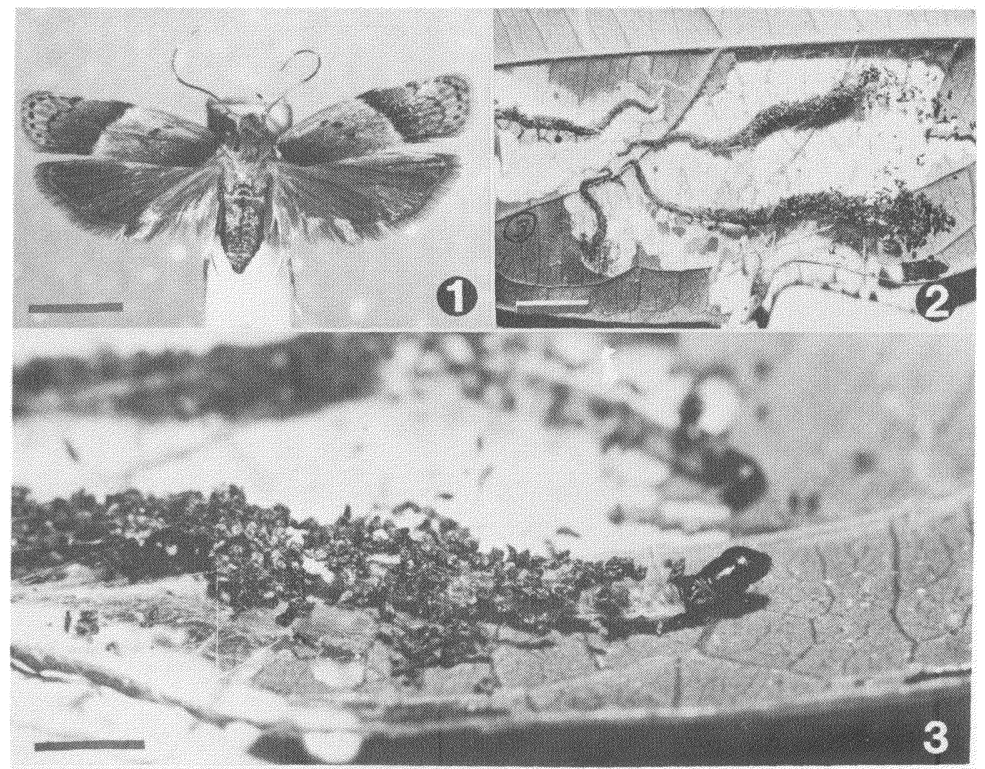

Figures 1-3. Antaeotricha sp. (Rearing lot 80-30). 1. Adult (individual no. 4). Scale $=3 \mathrm{~mm}$. 2. Silk and frass tubes on underside of leaf of Mascagnia nervosa. Scale $=7 \mathrm{~mm}$. 3. Final instar larva (individual no. 1) reaching out of its tube. Scale $=2 \mathrm{~mm}$.

Early instars (A, B) had pale-colored heads and green bodies. They constructed hard tubes of silk and frass, $0.5 \mathrm{~mm}$ in diameter, on the undersides of leaves. Most tubes were initiated along major leaf veins, a position which may offer protection to young larvae. The initial tube was dense and the larva inside could not be seen through its wall.

Subsequent instars extended the tube, each tube addition being wider and longer than previous portions.

Larvae did not leave their tubes to feed; they reached out (Figure 3 ) and scraped cells from the leaf surface.

Commencing with instar $\mathrm{C}$, larvae had dark heads and a pink mesothorax. The remainder of the body was green as before. Intermediate instars (C, D) continued construction of the hard tube, and also fed by scraping the leaf surface immediately in front of the tube opening.

Later instars (E-G) ate whole leaf. Portions of the tube, 
Table 1. Summary of variables for seven instars of individual no. 4 of Rearing lot 80-30. $(\mathrm{P}=$ pale, pink; $\mathrm{D}=$ dark; $\mathrm{G}=$ green; $\mathrm{S}=$ skeletonizer, soft; $\mathrm{H}=$ hard; $\mathrm{W}=$ eats whole leaf).

\begin{tabular}{lccccccc} 
& \multicolumn{7}{c}{ INSTAR } \\
& A & B & C & D & E & F & G \\
Instar duration (days) & $?$ & 5 & 4 & 4 & 3 & 5 & 8 \\
Head capsule width (mm) & 0.18 & 0.25 & 0.35 & 0.48 & 0.63 & 0.83 & 1.38 \\
Head capsule color & P & P & D & D & D & D & D \\
Mesothorax color & G & G & P & P & P & P & P \\
Feeding habit & S & S & S & S & W & W & W \\
Tube consistency & H & H & H & H & S & S & S
\end{tabular}

constructed by these instars, were soft and less dense than previous sections. The apical $2-3 \mathrm{~cm}$ of these tubes were extremely diffuse and the larvae inside could be seen clearly. Having consumed all nearby leaf, hungry larvae dismantled this diffuse portion and shifted it laterally until additional leaf surface was located, sometimes on other leaves of the same plant.

The final instar larva (G) (Figure 4) was about $7 \mathrm{~mm}$ long, lacked secondary setae; had prolegs on abdominal segments 3-6 and 10; crochets uniordinal, arranged in a circle; prespiracular wart of prothorax long, curving part way around spiracle, and bearing three setae; mesothorax with a single seta on tubercle $p i$; abdomen with setae alpha and beta widely separated, setae eta and kappa adjacent, seta beta on ninth segment placed higher up than alpha, and setae beta on ninth segment the same distance apart from one another across the dorsum as on previous abdominal segments; head with front extending about one-half the way to the vertex. Because the two sides of the mesothorax bore slightly different setation, on the specimen studied, both are illustrated in the setal maps (Figure 4). For ease of comparison, the map of the right mesothorax is shown in mirror image.

The day before pupation, final instar larvae abandoned their tubes and dropped to the floor of the cage. No cocoon was constructed.

The pupa (Figure 5) was ovate in outline, $5 \mathrm{~mm}$ long, $2 \mathrm{~mm}$ wide; with wings extending slightly beyond caudal margin of fourth abdominal segment; apical $1.3 \mathrm{~mm}$ of antennae adjacent on the meson except at their extreme tips, and bearing a distinctive raised 

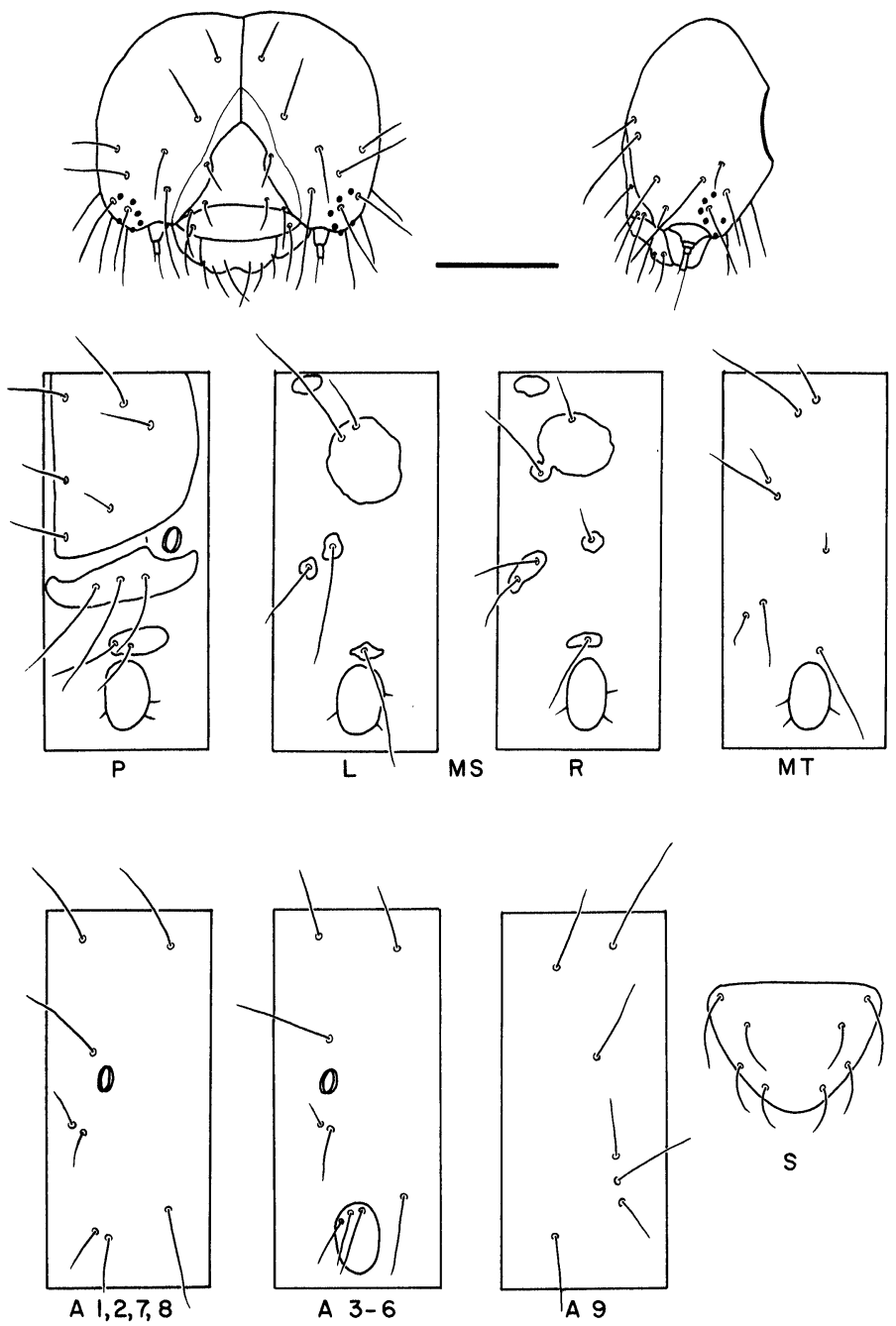

Figure 4. Antaeotricha sp. Final instar head capsule (front and lateral views), and setal maps. $\mathrm{P}=$ prothorax, $\mathrm{MS}=\operatorname{mesothorax}, \mathrm{L}=$ left, $\mathrm{R}=$ right, $\mathrm{MT}=$ metathorax, $\mathrm{A}=$ abdomen, $\mathrm{S}=$ suranal plate. Map of right mesothorax is shown in mirror image. Scale for head capsule $=0.5 \mathrm{~mm}$. 

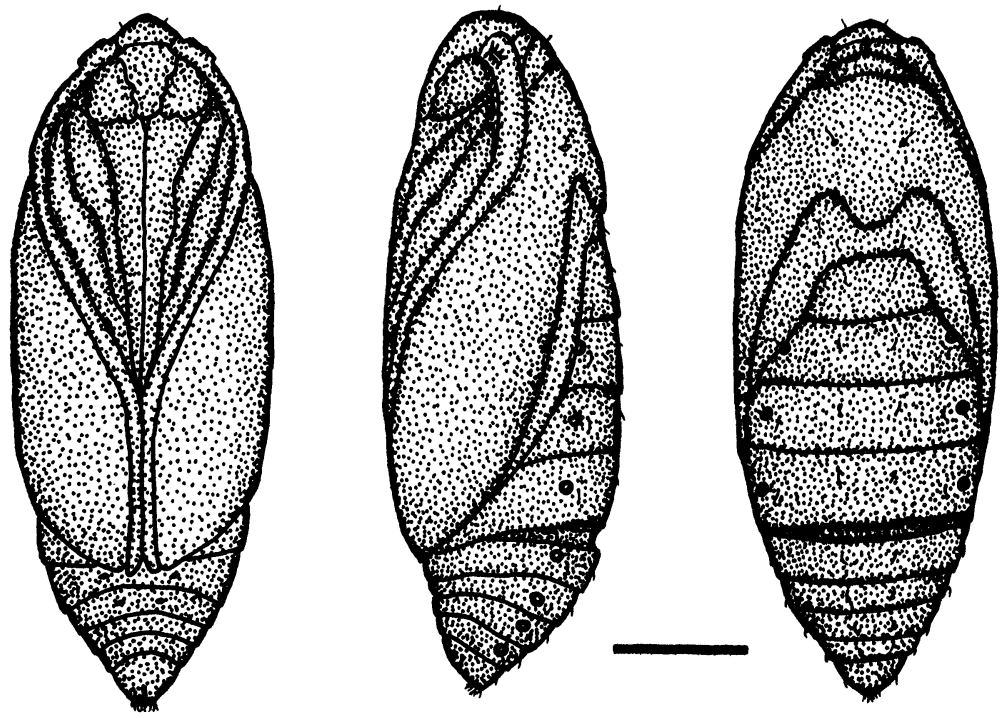

Figure 5. Antaeotricha sp. Pupa (ventral, lateral, and dorsal views). Scale $=1$ $\mathrm{mm}$.

structure on the scapes; mesothoracic legs and maxillae ending in the "V" formed by the meeting of the antennae; prothoracic legs slightly shorter than mesothoracic legs; labial palpi evident as tiny triangle between maxillae bases; fronto-clypeal and epicranial sutures distinct; abdominal segments 1-4 longer than others; spiracles evident on abdominal segments 2-8; cremaster of 8 weak setae.

Pupation lasted 10, 11, and 12 days for the three individuals reared. Total development time, for the individual collected as instar A, was 40 days. Allowing an additional three days for instar $A$, and four days for egg maturation, actual development time was probably close to 47 days.

Spread adults, pointed head capsules and pupal skins, and a larva and pupa in alcohol are in the collection of the author, deposited in the National Museum of Natural History, and are labelled as Rearing lot 80-30.

I would like to thank the Smithsonian Tropical Research 
Institute, Panama, for use of their facilities, J. B. Heppner (SI) for identification of the moth, and R. Silberglied for reading the manuscript.

\section{REFERENCE}

Watson, A. ANd P. E. S. Whalley

1975. The Dictionary of Butterflies and Moths in Color. xiv +296 pp., 405 figs. 

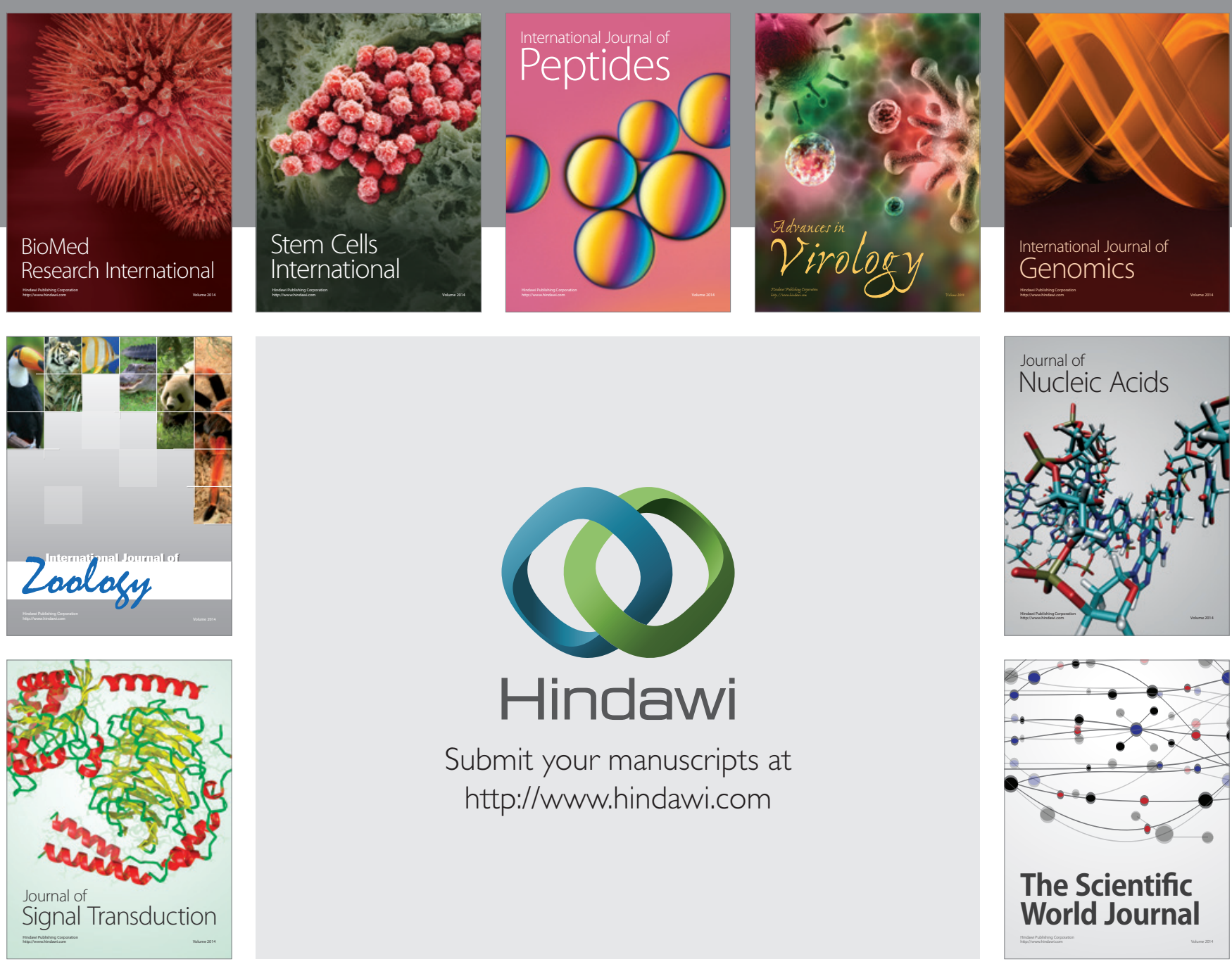

Submit your manuscripts at

http://www.hindawi.com
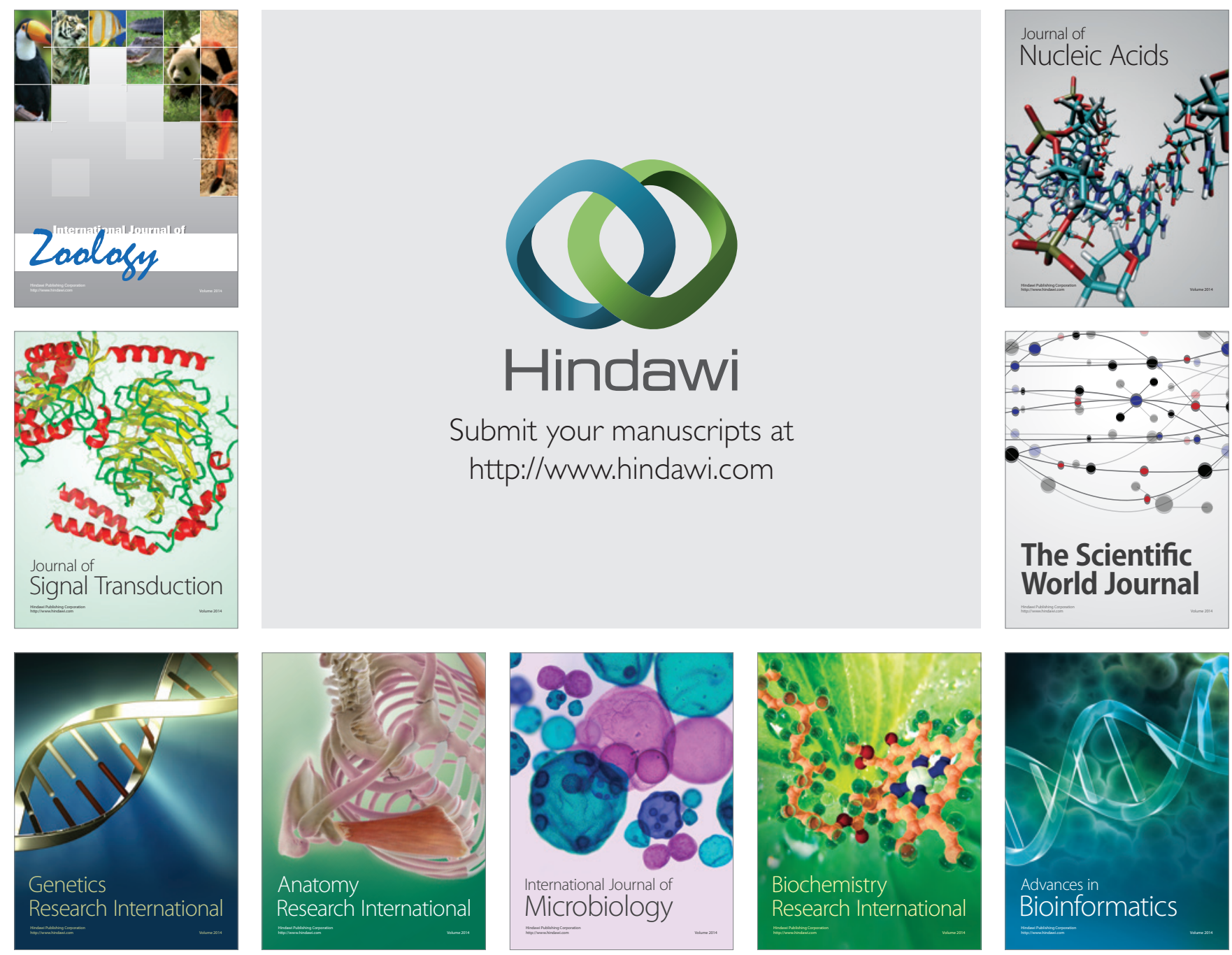

The Scientific World Journal
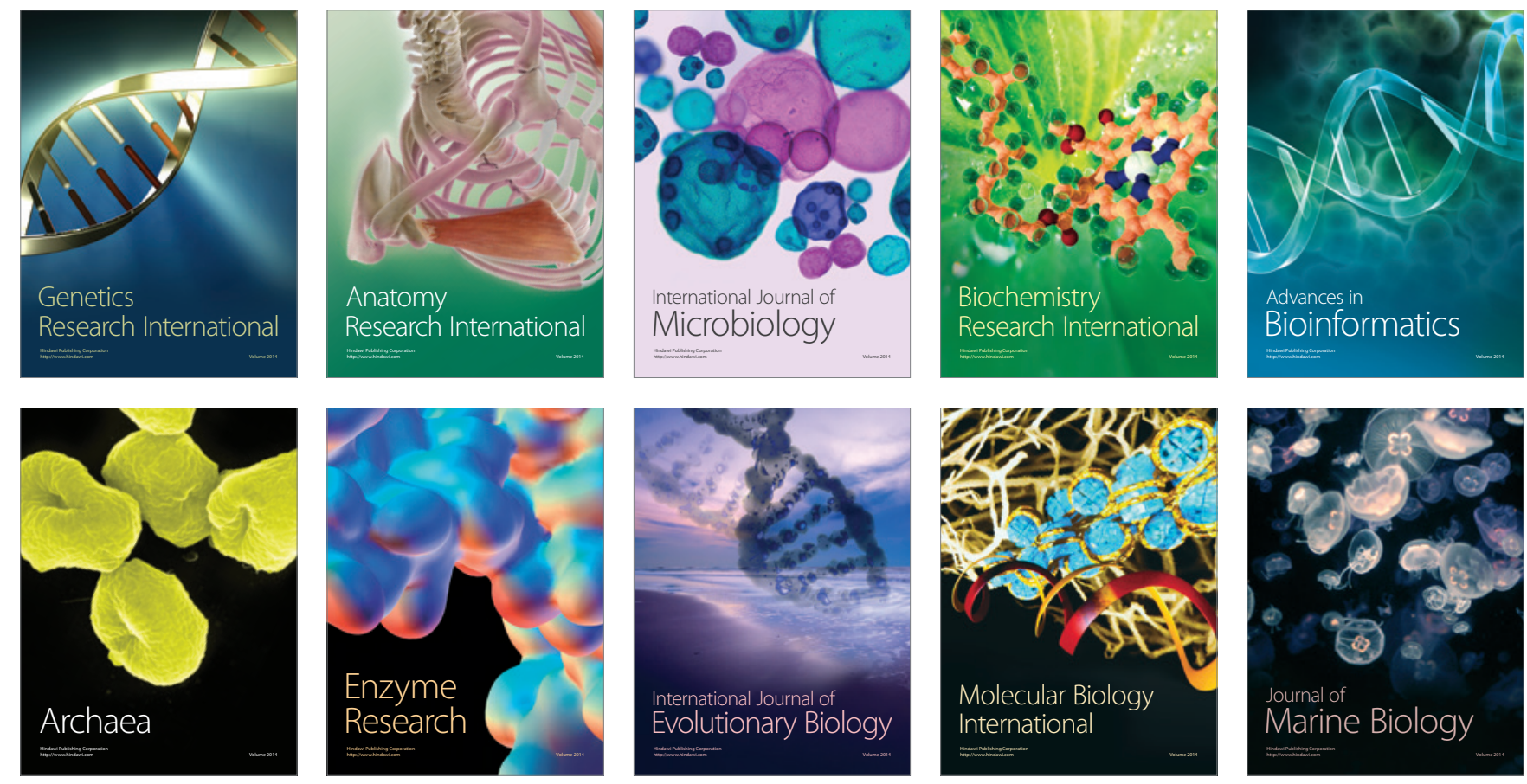